\title{
Is elimination of vertical transmission of HIV in high prevalence settings achievable?
}

\author{
Ameena Goga and colleagues argue that more realistic targets are needed to maintain \\ momentum on reducing vertical transmission in countries with a high HIV prevalence
}

T he idea of eliminating infectious diseases from society dates to the 18th century, when Edward Jenner envisioned elimination of smallpox through widespread vaccination. By 1997, the difference between control, eradication, and elimination had been defined (box 1). ${ }^{12}$ Of the perinatally acquired infections, only tetanus, HIV, and syphilis have been targeted for elimination. ${ }^{34}$

In 2011, the joint United Nations Programme on HIV/AIDS (UNAIDS) launched a global plan to eliminate new HIV infections among children by 2015 and to keep mothers with HIV infection alive. ${ }^{5}$ This prioritised elimination of vertical transmission of HIV (also known as mother-to-child transmission of HIV) in the 22 countries where $90 \%$ of the world's pregnant women with HIV reside (global plan priority countries). ${ }^{5}$ UNAIDS reported in 2016 that 1.2 million new HIV infections in children were averted in the 21 global plan priority countries in sub-Saharan Africa between 2009 and $2015 .^{6}$ Seven of these countries had reduced new HIV infections by more than $70 \%$ since 2009 (Burundi 84\%, Malawi 71\%, Mozambique $75 \%$, Namibia 79\%, South Africa 84\%, and Swaziland 80\%). ${ }^{6}$ UNAIDS highlighted

\section{KEY MESSAGES}

- An HIV infection case rate of $\leq 50 / 100$ 000 live births is needed to validate a country's elimination of vertical transmission as a public health problem

- The case rate heavily depends on maternal HIV prevalence, making elimination targets challenging in high prevalence settings even with low vertical transmission rates

- The case rate is an aspirational goal that may not be realised in the short to medium term in many high HIV prevalence settings

- To maintain momentum, policy makers should identify and monitor process indicators that increase opportunities for HIV prevention the urgent need for action to end the AIDS epidemic by 2030 as part of the sustainable development goals.

\section{What is meant by eliminating HIV?}

In 2012, a global consultation of over 70 experts, including country programme managers, agreed that one of the criteria to validate elimination of vertical transmission of HIV as a public health problem is a paediatric HIV incidence of $\leq 50$ cases per 100000 live births (box 2). ${ }^{4}$ This paediatric case rate was chosen because it was consistent with previous WHO elimination initiatives and expert consensus was that it was achievable (personal communication, C Hayashi, Unicef).

The decision to focus on eliminating rather than eradicating vertical transmission was taken because optimal interventions to prevent vertical HIV transmission are not $100 \%$ effective. Eliminating a disease as a public health problem is a powerful motivator and one that can be embraced without overpromising or setting programmes up for failure.

In 2014, the WHO published criteria to validate that a country has eliminated vertical transmission of HIV (box 2). ${ }^{4}$ The WHO guidance, updated in 2017 , recommends that each country should have adequate national monitoring and evaluation systems in place and adequate laboratory systems within the public and private sectors to assist with measurement. ${ }^{7}$

As of October 2017, the 10 countries or territories where elimination of vertical transmission of HIV has been validated are Cuba, Thailand, Armenia, Belarus, Anguilla, Montserrat, Cayman Islands, Bermuda, Antigua and Barbuda, and St Kitts and Nevis. ${ }^{7-10}$ However, none of these countries has a high HIV prevalence and none is a global plan priority country. In 2017, the concept of pre-elimination was introduced to recognise progress in preventing vertical transmission of HIV in high burden countries. ${ }^{11}$ To achieve validation for preelimination, $\geq 90 \%$ coverage across all three process indicator targets is needed and the rate of vertical transmission must be below $5 \%$. Importantly, there is no new target transmission case rate to qualify for pre-elimination. The complexity of vertical transmission of HIV means that achieving the child case rate to validate elimination will continue to be challenging in priority countries. Here we suggest how interest in the aspirational goal of eliminating vertical transmission of HIV can be maintained even though the case rate target seems unattainable in the short to medium term.

\section{What makes eliminating vertical transmission so complex?}

A comparison with neonatal tetanus, one of the three neonatal diseases targeted for elimination, shows the complexity of eliminating vertical transmission of HIV (see supplementary table on bmj.com). Neonatal tetanus is a non-transmissible disease caused by Clostridium tetani, a ubiquitous neurotoxin producing bacterium that contaminates infants' umbilical cords through

Box 1: Definitions of disease elimination

- Control-The reduction of disease incidence, prevalence, morbidity, or mortality to a locally acceptable level as a result of deliberate efforts. Continued intervention measures are required to maintain the reduction (eg, diarrhoeal disease)

- Elimination of disease-Reduction of a specified disease to zero incidence in a defined geographical area as a result of deliberate efforts. Continued intervention measures are required (eg, neonatal tetanus)

- Elimination of infections-Reduction to zero incidence of infection caused by a specific agent in a defined geographical area as a result of deliberate efforts. Continued measures are needed to prevent re-establishment of transmission (eg, measles, polio)

- Eradication-Permanent zero worldwide incidence of infections with a specific agent as a result of deliberate efforts. Intervention measures are no longer needed (eg, smallpox)

- Extinction-The specific agent no longer exists in nature or in the laboratory 


\section{Box 2: Criteria for elimination of vertical HIV transmission}

Impact criteria (to be sustained for one year)

- Vertical transmission of HIV in breastfed population $<5 \%$ (number of HIV infected children

divided by number of HIV exposed children tested for HIV at the end of breastfeeding)

- $\leq 50$ new child HIV infections per 100000 live births (case rate)

Process criteria (to be sustained for two years)

- Antenatal care coverage among all pregnant women $\geq 95 \%$

- HIV testing coverage among all pregnant women $\geq 95 \%$

- Antiretroviral treatment coverage for pregnant women with HIV infection $\geq 95 \%$

[1] All criteria have to be met for WHO to recognise elimination

unhygienic delivery practices. Neonatal tetanus progresses quickly and can take 3-21 days between infection and the appearance of disease. In contrast, children mainly acquire HIV infection from their mothers during pregnancy, labour, delivery, or breastfeeding. HIV may not be detectable for up to six weeks after infection, and it can take months to progress to AIDS.

$C$ tetani bacteria are transmitted by a single route, which does not depend on maternal infection or drug therapy. Consequently, neonatal tetanus is easily prevented by immunising women during pregnancy alongside hygienic delivery practices and proper cord care to prevent cord contamination. ${ }^{3}$ Preventing vertical transmission of HIV is more complex, requiring intervention from preconception to the end of breastfeeding. This includes primary prevention of HIV before, during,

Box 3: Discord between vertical transmission and target case rates ${ }^{10}$

In 2016-17, antenatal HIV prevalence in South Africa was roughly $32 \%$ and the national intrauterine vertical transmission of HIV rate was $0.9 \%$ at delivery. This corresponds to a HIV case rate at delivery of $288 / 100000$ live births ( $32 \%$ multiplied by 100000 live births (to calculate number of babies exposed to HIV) multiplied by $0.9 \%$ ). This value is well above the target of $\leq 50$ babies and is a measure of intrauterine HIV transmission, not transmission at the end of breastfeeding. ${ }^{16}$

At the provincial level, across South Africa, intrauterine vertical transmission rates ranged from $0.6 \%$ to $1.3 \%$, but new HIV infection case rates ranged from $168 / 100000$ to $325 / 100000$ live births. ${ }^{16}$

UNAIDS 2017 models estimate that vertical transmission rates range from $4 \%$ (Namibia and Uganda) to $21 \%$ (Angola) in the 22 global plan priority countries but case rates range from $85 / 100000$ live births in Burundi to $>2000 / 100000$ in Swaziland. and after pregnancy; prevention of initiation of antiretroviral therapy (ART); retention on ART for women with HIV; and retesting women without HIV to detect new infections early. Early antenatal care is also important to optimise general care, monitoring of maternal viral load, safe delivery practices, and infant postexposure prophylaxis. $^{12-15}$

\section{What makes the target case rate hard to achieve?} transmission, many countries with a high HIV prevalence have made good progress. However, they remain far from achieving a case rate of $\leq 50$ new HIV infections per 100000 live births at the end of breastfeeding, which is needed to validate elimination of vertical transmission. ${ }^{6}$ One reason for this it that the case rate for new child infections depends on maternal HIV prevalence as well as the vertical transmission rate. In settings where maternal HIV prevalence is high it can be very hard to attain the target case rate even when the vertical transmission rate is low (box 3 ).

To achieve a case rate of $\leq 50 / 100000$ live births when maternal HIV prevalence is $5 \%$, the vertical transmission rate needs to be $1 \%$ (fig 1). As long as maternal HIV prevalence is $\geq 10 \%$ the target case rate unwanted or unplanned pregnancies; early

Despite the complexity of reducing vertical

cannot be achieved, even if the vertical transmission rate is reduced to $1 \%$. Given the high prevalence of maternal HIV in the priority countries (roughly 30\% in South Africa, for example ${ }^{17}$ ) our sensitivity analysis raises questions around the usefulness of focusing on achieving the child case rate in the short term. In addition, we believe the gap between the current and target case rate is dampening the enthusiasm of funders, policy makers, managers, and frontline service providers because they know how far they are from the target.

\section{Maintaining momentum in the elimination agenda}

Given the substantial challenges in reaching the case rate target to achieve validation for elimination of vertical transmission of HIV, we suggest a greater focus on and recognition of process targets to maintain momentum. Policy makers and managers could track additional process indicators that increase opportunities for HIV prevention during the pre-elimination period. These can be tracked locally, regionally, and nationally through quality improvement processes that have been shown to be effective in routine settings. ${ }^{18}$

Data dashboards that track vertical transmission of HIV indicators have been associated with improved programme performance at national and facility levels. ${ }^{1819}$ These dashboards use red, amber, and green colour coding to illustrate achievement of targets. We suggest that policy makers or managers issue annual or biennial recognition for selected indicator measurements in relation to global goals. These selected indicators could be expanded beyond the current pre-elimination list to include those that measure increased coverage and uptake of maternal and child healthcare, on the assumption that increased coverage will reduce

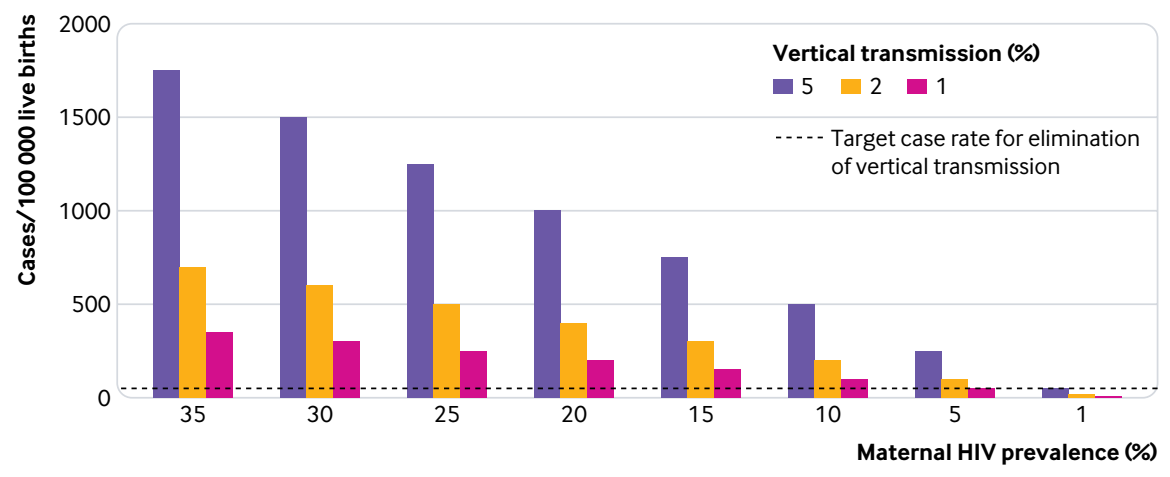

Fig 1 | Sensitivity analysis of child case rates, maternal HIV prevalence, and vertical transmission rate 
Box 4: Potential indicators to track progress in eliminating vertical transmission

- \% coverage for family planning (among all women)

- \% pregnant women booking antenatal appointments before 12 weeks' gestation

- \% pregnant women attending at least eight antenatal visits

- \% HIV testing coverage among pregnant women

- \% pregnant women having institutional deliveries

- \% HIV re-testing coverage among pregnant women without HIV at delivery

- \% ART coverage among pregnant or breastfeeding women with HIV

- \% viral suppression among pregnant or breastfeeding women with HIV taking ART

missed opportunities to prevent vertical transmission of HIV (box 4). We suggest six colour coded levels for recognition against global goals: red ( $0-25 \%$ coverage), blue $(>25-50 \%$ coverage), bronze $(>50-75 \%$ coverage), silver ( $>75-89 \%$ coverage), gold (90-94\%), and platinum (>94\% coverage). These suggested cut-offs are based on quartiles, with the upper quartile split to reflect the pre-elimination and elimination criteria set out in WHO guidance.

This system could help maintain momentum by providing achievable targets towards eliminating vertical HIV infection. It could also be used to identify gaps with monitoring and attainment of targets and to guide the development of interventions to address these gaps.

Competing interests: We have read and understood BMJ policy on declaration of interests and have no relevant interests to declare. The article was funded by the South African Medical Research Council (SAMRC). The views expressed in this paper are those of the authors not of the funders.

Contributors and sources: AG conceptualised the paper and led the writing. All authors contributed to the ideas in the paper, contributed to all drafts, and approved the final version.

Provenance and peer review: Commissioned; externally peer reviewed.

This article is part of a series proposed by the South African Medical Research Council and commissioned by The BMJ. The BMJ retained full editorial control over external peer review, editing, and publication. Open access fees are funded by SAMRC.

Ameena Goga, professor ${ }^{1,2}$

Yagespari Singh, researcher ${ }^{1}$

Debra Jackson, technical adviser ${ }^{3,4}$

Yogan Pillay, deputy director general ${ }^{5}$

Sanjana Bhardwaj, technical adviser ${ }^{6}$

Witness Chirinda, researcher ${ }^{1}$

Chika Hayashi, senior adviser $^{7}$

Shaffiq Essajee, senior adviser ${ }^{4}$

Priscilla Idele, deputy director ${ }^{8}$
${ }^{1}$ Health Systems Research Unit, South African Medical Research Council, South Africa

${ }^{2}$ Department of Paediatrics, University of Pretoria, Pretoria, South Africa

${ }^{3}$ School of Public Health, University of the Western Cape, Cape Town, South Africa

${ }^{4}$ Health Section, Unicef, New York, USA

${ }^{5}$ National Department of Health, Pretoria, South Africa

${ }^{6}$ Health Section, Unicef South Africa, Pretoria, South Africa

${ }^{7}$ Data and Analytics Section, Unicef, New York, USA

${ }^{8}$ Unicef Office of Research, Innocenti, Florence, Italy

Correspondence to:A Goga Ameena.Goga@mrc.ac.za

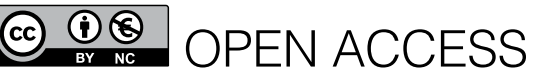

This is an Open Access article distributed in accordance with the Creative Commons Attribution Non Commercial (CC BY-NC 4.0) license, which permits others to distribute, remix, adapt, build upon this work non-commercially, and license their derivative works on different terms, provided the original work is properly cited and the use is non-commercial. See: http://creativecommons.org/licenses/by-nc/4.0/.

\section{Check for updates}

1 Dowdle WR. The principles of disease elimination and eradication. Bull World Health Organ 1998;76(Suppl 2):22-5.

2 Dowdle WR, Cochi SL. The principles and feasibility of disease eradication. Vaccine 2011;29(Suppl 4):D703. doi:10.1016/j.vaccine.2011.04.006

3 Unicef, UNFPA, World Health Organization. Achieving and sustaining maternal and neonatal tetanus elimination: strategic plan 2012-2015. 2011. http://www.who.int/immunization/diseases/ MNTEStrategicPlan_E.pdf.

4 World Health Organization. Global guidance on criteria and processes for validation: elimination of mother-to-child transmission of HIV and syphilis. 2014. http://www.who.int/hiv/pub/emtct-validationguidance/en/

5 UNAIDS. Global plan towards the elimination of new HIV infections among children by 2015 and keeping their mothers alive. 2011. http://files.unaids.org/ en/media/unaids/contentassets/documents/ unaidspublication/2011/20110609_JC2137 Global-Plan-Elimination-HIV-Children en.pdf
6 UNAIDS. On the fast track to an AIDS free generation: the incredible journey of the global plan towards the elimination of new HIV infections among children by 2015 and keeping their mothers alive. 2016. http://www.aidsdatahub.org/fast-track-aids-freegeneration-unaids-2016

7 World Health Organization. Global guidance on processes and criteria for validation: elimination of mother-to-child transmission of HIV and syphilis. 2nd ed. 2017. https://www.who.int/reproductivehealth/ publications/emtct-hiv-syphilis/en/

8 World Health Organization SEARO. Thailand is first country in Asia to eliminate mother-to-child transmission of HIV and syphilis, 2016. www.searo. who.int/mediacentre/releases/2016/1627/en/

9 World Health Organization. Thailand, Belarus and Armenia eliminate mother-to-child transmission of HIV. 2016. http://www.who.int/hiv/mediacentre/ news/emtct-validation-2016/en/

10 Goga A, Dinh T, Essajee S, et al. What will it take for the global plan priority countries in sub-Saharan Africa to eliminate mother-to-child transmission of HIV?BMC Infect Dis [forthcoming].

11 Barigye H. Evaluation of Namibia's PMTCT programme-2016. https://www.unicef.org/ evaldatabase/index 95226.html

12 World Health Organization. Prevention of HIV in infants and young children: review of evidence and WHO's activities. 2002. https://www.popline.org/ node/236104

13 World Health Organization. Strategic approaches to the prevention of HIV infection in children: Report of a WHO meeting, Morges, Switzerland, 20-22 Mar 2002. http://www.who.int/hiv/mtct/ StrategicApproaches.pdf

14 World Health Organization. Use of antiretroviral drugs for treating pregnant women and preventing HIV infection in infants. 2012. http://www.who.int/hiv/ $\mathrm{pub} / \mathrm{mtct} / \mathrm{programmatic}$ update2012/en/

15 World Health Organization, Unicef. 2016 guideline update on HIV and infant feeding. 2016. http:// repronetafrica.org/2016-guideline-update-on-hivand-infant-feeding/

16 Goga A, Chirinda W, Ngandu N, et al. Closing the gaps to eliminate mother-to-child transmission of HIV (MTCT) in South Africa: understanding MTCT case rates, factors that hinder the monitoring and attainment of targets, and potential game changers. S Afr Med J 2018;108(Suppl 1):S17-24. doi:10.7196/SAMJ.2017.v108i3b.12817

17 National Department of Health. The 2013 national antenatal HIV sentinel survey. 2015. https://www. health-e.org.za/wp-content/uploads/2016/03/DeptHealth-HIV-High-Res-7102015.pdf

18 Bhardwaj S, Barron P, Pillay Y, et al. Elimination of mother-to-child transmission of HIV in South Africa: rapid scale-up using quality improvement. $S$ Afr Med ) 2014;104(Suppl 1):239-43. doi:10.7196/ SAMJ.7605

19 Unicef, South African Medical Research Council, Ministry of Health. "Together we can improve": a case study of join community-facility review of PMTCT dashboards in Malawi. 2016. https://www. childrenandaids.org/sites/default/files/2017-04/ Malawi\%20Case\%20Study_PMTCT_UNICEF-2016. pdf

Cite this as: BMJ 2019;364:1687 http://dx.doi.org/10.1136/bmj.l687 